\title{
Information theory based methods to estimate the functional connectivity in dissociated neuronal networks Matteo Garofalo*1, Thierry Nieus ${ }^{1}$, Paolo Massobrio ${ }^{2}$ and Sergio Martinoia ${ }^{1,2}$
}

\author{
Address: ${ }^{1}$ Neuroscience and Brain Technology Department, Italian Institute of Technology, Genova, Italy and ${ }^{2}$ Department of Biophysical and \\ Electronic Engineering, University of Genova, Genova, Italy \\ Email: Matteo Garofalo* - matteo.garofalo@iit.it \\ * Corresponding author
}

from Eighteenth Annual Computational Neuroscience Meeting: CNS*2009

Berlin, Germany. 18-23 July 2009

Published: I 3 July 2009

BMC Neuroscience 2009, I0(Suppl I):PI09 doi:I0.II86/I47|-2202-I0-SI-PI09

This abstract is available from: http://www.biomedcentral.com//47I-2202/I0/SI/PI09

(c) 2009 Garofalo et al; licensee BioMed Central Ltd.

\section{Introduction}

Large random networks of in vitro cortical neurons coupled to Micro Electrode Arrays (MEAs) can be used as a model for studying the network mechanisms of information coding, learning and memory [1]. To better investigate the neuronal dynamics of these complex systems, one must quantify the couplings among pairs of neurons based upon electrophysiological measurements (functional connectivity).

\section{Methods}

We estimated the functional connectivity of highly connected neuronal networks by means of cross correlation (CC), joint entropy (JE), mutual information (MI), and transfer entropy (TE) [2]. Since MI is symmetrical, we built an MI function delaying the peak trains in order to detect directional flow of information. JE is based on the cross inter spike intervals and it has been applied for the first time in this context. The methods performances were evaluated by ROCs (Receiver Operating Characteristic) and by an ad hoc method named PPC (Positive Precision Curve), on a neuronal network model made up of excitatory and inhibitory (20\%) neurons.

\section{Results}

On simulated networks, TE showed the best performances while JE might provide an adequate alternative (Figure 1A). However, on experimental data recorded by MEAs, CC showed a good agreement with TE (Figure 1B). MI, instead, showed the worst performances both on simu- lated data and experimental recordings. Connectivity maps (Figure 1C) can be obtained by the identification of the highest connectivity methods values.

\section{Discussion}

PPCs allow to evaluate the absolute number of True Positives (TP) and False Positives (FP) and provide further information regarding their identification and about how to maximize the methods performances. The PPCs (Figure 1A) evaluated on the simulated models are entirely negative due to the complexity of the analyzed system. On real data, we estimated the overlap level (Figure 1B) among the connectivity methods discovering a high level of agreement between TE and CC on identifying some common FPs. It could be interpreted as the capability of such methods to detect some indirect connections.

\section{References}

I. Marom S, Shahaf G: Development, learning and memory in large random networks of cortical neurons: lessons beyond anatomy. Quart Rev Biophys 2002, 35:63-87.

2. Gourèvitch B, Eggermont J]: Evaluating information transfer between auditory cortical neurons. I Neurophysiol 2007, 97:2533-2543. 
A

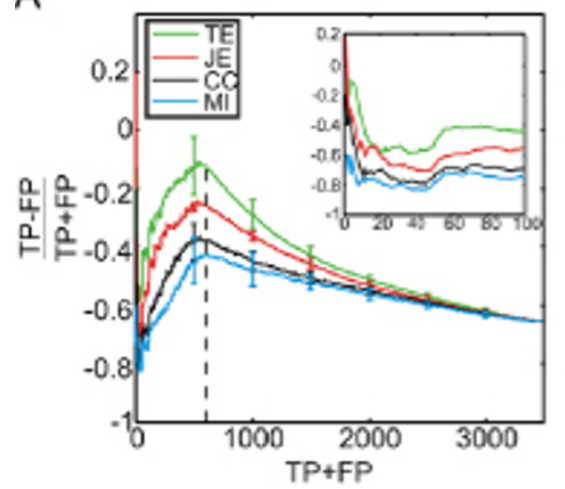

B

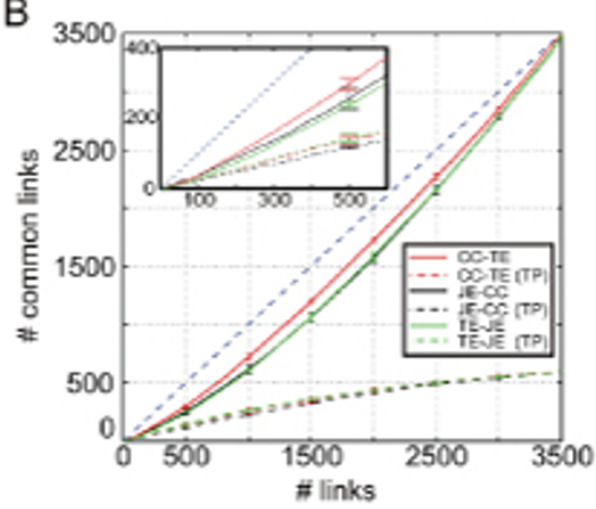

C

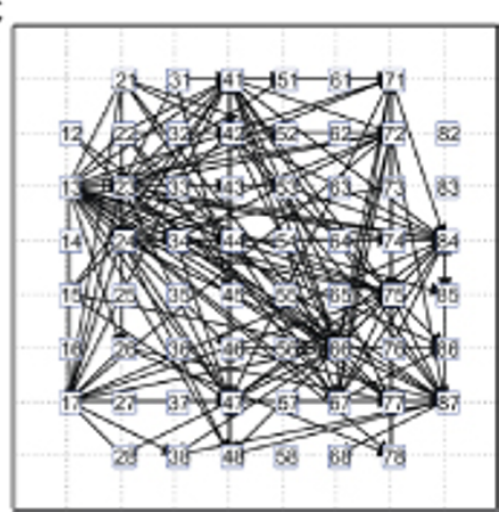

Figure I

(A) PPCs relative to the simulated models. (B) Overlap curves from experimental data (dashed curves correspond to TPs commonly identified). (C) A connectivity map obtained by TE (200 links) on experimental data.

Publish with Bio Med Central and every scientist can read your work free of charge

"BioMed Central will be the most significant development for disseminating the results of biomedical research in our lifetime. " Sir Paul Nurse, Cancer Research UK

Your research papers will be:

- available free of charge to the entire biomedical community

- peer reviewed and published immediately upon acceptance

- cited in PubMed and archived on PubMed Central

- yours - you keep the copyright 